UDC 159.92

LBC 88.3

\title{
SUBJECTIVE WELL-BEING IN THE CONTEXT OF RUSSIAN FAMILY LIFE
}

\author{
Oksana V. Lyusova \\ Volgograd Academy of Physical Culture, Volgograd, Russian Federation
}

\begin{abstract}
Single mothers in Russia are not fully accepted by the traditional modern society. The image of a woman raising children alone is less attractive than that of a married mother. In addition to the negative impact on the personality characteristics of children brought up in single families single motherhood is associated with the low level of subjective well-being of the woman herself. The problem of happiness (subjective well-being) excited the minds of great scientists from ancient times. This phenomenon has received different names in science: subjective well-being, psychological well-being, emotional well-being, life satisfaction, similar names: psychological health, psychological maturity of the individual, personal maturity. Theoretical analysis of scientific approaches allows to identify the structure and criteria of subjective well-being of a person, to reveal the essence of this concept. The article makes an attempt to identify methods of psychological assistance to single mothers. Particular attention is paid to the methods of art therapy. The purpose, tasks, mechanisms (projection, symbolism, interiorization), advantages of art therapy in work with women are designated, among which ecological compatibility and care in relation to human experiences are recognized as the most important. The main task of art therapy is to achieve the harmonization of personality, balance between the main structures of the human personality where defined tasks, functions, mechanisms of metaphorical associative maps are considered as tools of art therapy. The complex of occupations to increase subjective well-being of single mothers is determined in the basis of which the idea of influence on a time axis of subjective representation of the person about the way of life and structure of the subjective well-being including social, spiritual, material, physical, psychological components is put. Objectives for work with each of the components of subjective well-being, and three temporal regions of human consciousness are set. Work on the proposed matrix of techniques can be carried out in both individual and group forms.
\end{abstract}

Key words: single mothers, subjective well-being, art therapy, metaphorical associative maps, projection, metaphor.

УДК 159.92

ББК 88.3

\section{СУБЪЕКТИВНОЕ БЛАГОПОЛУЧИЕ В КОНТЕКСТЕ ЖИЗНЕДЕЯТЕЛЬНОСТИ РОССИЙСКОЙ СЕМЬИ}

\author{
Оксана Валерьевна Люсова
}

Волгоградская академия физической культуры, г. Волгоград, Российская Федерация

\begin{abstract}
Аннотация. Одинокие матери в России не принимаются полностью традиционным современным обществом. Имидж женщины, воспитывающей детей в одиночку, не столь привлекателен, нежели имидж замужней матери. Кроме негативного влияния на особенности личности детей, воспитанных в неполных семьях, одинокое материнство связано с низким уровнем субъективного благополучия самой женщины. Проблема счастья (субъективного благополучия) волновала умы великих ученых с древности. Это явление в науке ס балучило разные названия: субъективное благополучие, психологическое благополучие, эмоциональное агополучие, удовлетворенность жизнью; близкие названия: психологическое здоровье, психологическая зрелость личности, личностная зрелость. Теоретический анализ научных подходов позволяет выделить структуру и критерии субъективного благополучия человека, выявить суть этого понятия. В статье предпринята попытка обозначить методы психологической помощи одиноким матерям. Особое внимание уделяется методам арттерапии. Обозначены цель, задачи, механизмы (проекция, символизм, интериоризация), достоинства арттерапии в работе с женщинами, среди которых важнейшим признаны экологичность и бережность
\end{abstract}




\section{РОССИЙСКАЯ СЕМЬЯ}

по отношению к человеческим переживаниям. Главная задача арттерапии - достижение гармонизации личности, баланса между основными структурами личности человека. Определены задачи, функции, механизмы работы метафорических ассоциативных карт как одного из инструментов арттерапии. Приведен комплекс занятий для повышения субъективного благополучия одиноких матерей, в основе которого заложена идея о воздействии на временную ось субъективного представления человека о своем жизненном пути и структуре субъективного благополучия, включающего в себя социальный, духовный, материальный, физический, психологический компоненты. Определены задачи для работы с каждым из компонентов субъективного благополучия и тремя временными областями самосознания человека. Работа по предложенной матрице техник может проводиться как в индивидуальной, так и групповой форме.

Ключевые слова: одинокие матери, субъективное благополучие, арттерапия, метафорические ассоциативные карты, проекция, метафора.

В последние десятилетия представления о семье и браке претерпели значительные изменения. Особенно очевидным явилось изменение роли женщины в семье и обществе. Все чаще женщины выбирают в одиночку воспитывать ребенка. Этот факт позволяет им естественно воспринимать свое одинокое материнство, однако научные исследования называют такое материнство ненормативным репродуктивным поведением. И.Н. Рассказова [12] указывает на связь между отсутствием супруга и чувством одиночества, что влечет за собой в качестве компенсации этого чувства неадекватные паттерны поведения - доминирование и соперничество, которые чаще встречаются у мужчин, чем у женщин. Исследования имиджа матери показали, что общество допускает и считает привлекательным одинокое материнство в зрелом возрасте, но такой имидж ниже имиджа замужней женщины. Выявлено, что воспитание ребенка или детей в одиночку негативно сказывается на психологическом благополучии женщины, на восприятии собственной жизни и себя [14].

Многие исследователи в России и за рубежом (М. Аргайл, Н. Бредборн, Е. Динер, О.С. Копина, Г.Л. Пучкова, Дж. Карпара, Н.А. Растригина, О.С. Савельева, Р.М. Шамионов, П.И. Яничев и др.) предпринимали попытки изучить человеческое счастье. В науке этот феномен известен как: психологическое благополучие, субъективное благополучие, удовлетворенность жизнью, психологическое здоровье и т. д. Проблема счастья волновала умы великих с древности. Например, Аристотель говорил о желании и движении человека к счастью как критерию нравственности [1]. Е. Динер, С. Динер [21] выделили структурные компоненты описываемого понятия: положительные эмоции, удовлетворенность, негативные эмоции. Структура субъективного благополучия по С.Д. Рифф включает в себя: в целом положительное отношение к своей прошлой жизни и себе как личности, приносящие удовольствие отношения с другими людьми, вера в себя, умение жить (жизненная компетентность), осознавание имеющихся целей и смыслов, удовлетворенность самореализацией [22]. М. Аргайл указывает на связь счастья и имеющихся социальных связей, работы, внутренней мотивации (источник которой находится внутри субъекта), материального благополучия, статуса в обществе [17]. Дж. Капрара находит связь между субъективным благополучием, целью и смыслом жизни, наши исследования также подтверждают это положение [18]. М. Чиксентмихайи рассматривает состояние потока как переживание, синонимичное субъективному благополучию [19]. Теория Э. Диси [20] указывает на возможность порождения состояния субъективной удовлетворенности внутренней мотивацией, инициируемой самим субъектом.

Л.В. Куликов усматривает в структуре субъективного благополучия такие компоненты, как физическое, социальное, материальное, психологическое, духовное [6]. Р.М. Шамионов [16] указывает на субъективное благополучие как состояние динамического равновесия, которое может быть достигнуто переживаниями удовлетворенности в разных сферах. Он выделяет модусы субъективного благополучия: модус социального самоопределения, модус смыслового, модус физического и психологического здоровья, модус профессионального самоопределения и роста, 
модус личностного (характерологического) благополучия. Эти модусы связаны с тремя сферами самосознания по У. Джеймсу: социальное, физическое, психологическое.

С точки зрения В.Г. Пучковой [11], когнитивный, эмоционально-оценочный, мотивационно-поведенческий компоненты входят в состав субъективного благополучия (счастья). О.А. Елисеева связывает между собой субъективное благополучие и личностный рост как очень близкие явления [4]. С.Л. Братченко и М.Р. Миронова выделяют критерии: понимание и принятие других людей, успешность социализации, умение творчески адаптироваться, решая жизненные задачи (интерпсихические критерии); полное принятие себя, осознание собственных переживаний, самопонимание, свобода, предполагающая ответственность, целостность, динамичность (интрапсихические критерии) [2]. И.А. Джидарьян видит связь между благополучием субъекта и его способностью и желанием меняться, развиваться [3].

Таким образом, сейчас в российском обществе явно видно противоречие между массовым явлением одинокого материнства, недостаточно толерантным отношением к этому явлению большинства общества и снижением уровня психологического благополучия, недооценкой или низкой оценкой себя и своей жизни женщинами, воспитывающими детей в одиночку. Потому перед психологической наукой и практикой встала задача, заключающаяся в психологической помощи одиноким матерям. Одним из эффективных методов такой помощи является арттерапия.

Арттерапия - метод психокоррекции и психотерапии, который позволяет экологично, мягко, корректно, бережно работать с психологическими трудностями женщины через творчество (художественное, музыкальное, литературное, танцевальное и т. д.). Методы арттерапии основываются на теории 3. Фрейда о бессознательном и символизме, теории К.Г. Юнга о персональных и универсальных символах, положении об интериоризации Л.С. Выготского как возможности манипулирования и овладения символами и аналогично тому овладении собой, своей психикой. На сегодняшний день арттерапия расширила теоретическую базу за счет моделей формиро- вания личности К. Роджерса и А. Маслоу и экзистенциальных теорий развития личности, например, между бессознательным и сознательным, между «хочу» и «могу», между потребностями и ресурсами, между активностью субъекта и реактивностью как компонента среды. Механизмами арттерапии являются:

- осознание психических процессов и конфликтов, расположенных в бессознательном, их воплощение в художественных образах;

- исследование своего внутреннего мира, переживаний, конфликтов, осознание их, управление ими;

- развитие умения проживания себя в мире, состояние «здесь и теперь»;

- укрепление волевой части личности, преображение окружающей действительности и своих собственных психологических эмоциональных состояний, развитие авторства собственной жизни, субъектности.

Задачами арттерапии признаны:

1) отреагирование эмоциональных состояний в процессе художественного творчества;

2) обогащение терапевтического процесса невербальными образами;

3) психоаналитическая проработка вытесняемых мыслей и чувств;

4) усиление навыков саморегуляции при работе с художественными образами;

5) сконцентрированность на актуальных ощущениях и чувствах в противовес хаотичному потоку мыслей, часто иррациональных;

6) укрепление адекватной самооценки при развитии творческих способностей;

7) улучшение эмоционального состояния в процессе проведения арттерапевтической сессии;

8) наделение личностным смыслом необходимых для разрешения жизненных задач знаний, принципов, правил, норм в процессе творчества, присвоение особой ценности.

Арттерапия проводится в индивидуальной и групповой форме. В зависимости от задачи терапии занятия могут носить структурированный и неструктурированный характер; арттерапия применяется в активной (создание произведений искусства) и пассивной (использование продуктов искусства) формах.

Творческая деятельность в процессе ее осуществления формирует самого человека как творца, субъекта, что позволяет менять 


\section{РОССИЙСКАЯ СЕМЬЯ}

окружающую среду, но и вместе с этим менять самого себя как субъекта, используя механизм интериоризации. В этом заключается основной механизм арттерапии - психологические изменения человека, женщины. В последнее время использование метафорических ассоциативных карт как одного из видов арттерапии получило особенно широкое распространение среди психологов-практиков.

Метафорические ассоциативные карты, используя механизм проекции, диагностируют психологическое и эмоциональное состояние для эффективной терапевтической работы с женщинами-клиентами. Особенность метафорических ассоциативных карт (МАК) заключается в независимости от культуры, и потому они эффективны для работы с любыми клиентами (пол, национальность, возраст, социальное положение не влияют на эффективность). Использование в работе с клиентом МАК позволяет одновременно задействовать три сферы: эмоциональную, ментальную и телесную, создавая безопасность и безоценочность во взаимодействии, хороший контакт. При раскрытии сущности механизмов работы МАК необходимо обратиться к таким понятиям, как: «проекция», «метафора», «архетипы», символизм образов (персональный и архитипический), «идентификация», «картина мира», «ассоциации», «инсайт», «фигура и фон», «игра», телесные реакции, диссоциация от проблем, перенос в реальность и некоторые другие [9]. Как проективный инструмент, МАК позволяют обнаружить эмоционально заряженные темы прошлого, настоящего, будущего. Метафорические карты влияют на восприятие человека через различные модальности, способствуют разнообразным ассоциациям (визуальным и нарративным), что является базой психологических интервенций. Использование МАК способствует облегчению протекания терапии за счет ослабления психологических защит, инсайтов, осознания вытесненного бессознательного материала, проработке осознанного, трансформации в метафорической форме внутренних конфликтов, уточнению картины мира. К. Маданес говорит о том, что все аспекты поведения человека могут быть описаны при помощи аналогий, метафор разного уровня обобщения [8]. Метафора действует не явно, не прямо, одна- ко, объединяясь вместе с внутренними актуальными переживаниями, вызывает инсайт, разрешает психологические трудности. За этим следует перенос в реальность, в жизненную ситуацию. Д. Трунов [15] описывает функции, которые выполняют психотерапевтические метафоры (ПТМ) в терапии:

1. Экспрессивная - выражает невербализуемые переживания, способствует экономичности.

2. Диагностическая - используется в проективных методиках.

3. Диссоциирующая функция заключается в отделении проблемы от личности, вынесении ее вовне, экстериоризации.

4. Поясняющая функция - в яркой форме образов проясняются психологические закономерности.

Использование метафоры в терапевтической работе экономит время и силы и делает психотерапию безопасной, что способствует достижению контакта с клиентом, вносит разнообразие в набор инструментов психолога [5]. Визуальный ряд МАК позволяет манипулировать образами клиента, а вместе с метафорическим нарративом усиливают эффект терапевтических интервенций.

Опираясь на положения гуманистической (Ш. Бюлер, А. Маслоу, Р. Мэй, К. Роджерс, В. Франкл и др.) и позитивной психологии (М. Селигман), любой индивид имеет в себе множество ресурсов. М. Селигман предлагает в процессе терапии фокусироваться на этих pecypcax, ощущении благополучия, оптимизме, жизнестойкости, источниках субъективного ощущения счастья, позитивных качествах клиента и, проанализировав включенность в социальные связи, способствующие удовлетворенности жизнью и личностному росту, логично подойти к решению психологической проблемы [13]. В соответствии с этим терапия с использованием метафорических ассоциативных карт предполагает следующие моменты:

- поиск ресурса внутри личности клиента;

- отношения партнерства «субъект субъект»;

- актуализация силы, возможностей, способностей, ресурсов клиента;

- поиск ресурсов в решении психологических трудностей, либо развитие ресурса, и нового паттерна поведения из задатков [13]. 
Использование метафорических ассоциативных карт связано с «инсайтом». Автор клиентцентрированной терапии К. Роджерс указывал, что инсайт объединяет в себя следующее: мгновенное схватывание взаимосвязей между тем, что уже было известно по одному, а не вместе; принятие своих естественных желаний (самопринятие спонтанности). Настоящий инсайт заключается в выборе тех целей, которые смогут удовлетворить клиента наилучшим образом [10]. МАК помогают клиенту расширить знания о себе в иерархии значимых переживаний, знания о своей внутренней жизни для ее гармонизации. Необходимо отметить, что к метафорическим картам можно применить принцип фигуры и фона из гештальт-терапии Ф. Перлза [10], то есть ни одна карта не имеет четкого или одного значения, тем более нельзя говорить о «правильном» значении карты.

Задачи, которые могут решить метафорические ассоциативные карты как инструмент арттерапии, заключаются в следующем: исследование внутреннего пространства человека, его проблемных мест при помощи техники ассоциаций на визуальные образы карт; интервенции при помощи метафоры, открывающие путь к ресурсам клиента. В терапевтической сессии с использованием МАК достигаются задачи установления доверительного контакта; актуализация значимых переживаний клиента в настоящем времени; блокирование тревожности и возможность обращаться к глубинным структурам в терапевтической сессии; соприкосно- вение с внутренними частями личности; самоисследование своих ценностей и руководящих мотивов; обнаружение вытесненных в бессознательное конфликтов; структурирование проблемы; поиск путей решения психологической проблемы и внутренних ресурсов; расширение картины мира; получение обратной связи в форме метафоры.

Опираясь на теоретический анализ представленных подходов к психологическому благополучию одиноких матерей, мы предлагаем матрицу терапевтических интервенций с помощью метафорических ассоциативных карт на эмоциональную сферу женщин, которая представлена в таблице. Цель данного комплекса - оптимизация субъективного благополучия женщин, одиноко воспитывающих детей.

Матрица работы с женщинами составлена на основе компонентов субъективного благополучия, выделенных Л.В. Куликовым, и концепций проектирования будущего [6], основанием которой послужило воздействие на временную ось [7]:

- интервенция в субъективное прошлое осознание жизненного стиля (индивидуальная психология А. Адлера), освобождение сознания от неадаптивных стереотипов через механизм осознания (психоанализ, транзактный анализ), осознание собственных дезадаптивных убеждений с помощью когнитивной психотерапии;

- интервенция в субъективное настоящее - оптимизация эмоционального состояния с помощью методов и техник гештальттера-

Матрица МАК-техник работы с одинокими матерями для повышения субъективного благополучия

\begin{tabular}{|c|c|c|c|c|}
\hline \multirow{2}{*}{$\begin{array}{l}\text { Модусы } \\
\text { времени }\end{array}$} & \multicolumn{4}{|c|}{ Сферы жизни } \\
\hline & социальное & духовное & материальное & психологическое \\
\hline Прошлое & Моя история успеха & $\begin{array}{l}\text { Чистка чердака } \\
\text { Родовой герб } \\
\text { Женщины моего рода }\end{array}$ & Ресурсное место & $\begin{array}{l}\text { Работа с негативом } \\
\text { Сундук с сокровищами } \\
\text { Исцеление внутреннего } \\
\text { ребенка }\end{array}$ \\
\hline Настоящее & $\begin{array}{l}\text { Моя команда } \\
\text { Мои маски } \\
\text { Я и мои роли }\end{array}$ & Женская энергия & $\begin{array}{l}\text { Проблема-решение } \\
\text { Я и деньги }\end{array}$ & $\begin{array}{l}\text { Кто Я? } \\
\text { Моя жизнь } \\
\text { Слепые пятна } \\
\text { Мои субличности } \\
\text { Квадрат Декарта } \\
\text { Мои возможности }\end{array}$ \\
\hline Будущее & $\begin{array}{l}\text { Текущее-желаемое } \\
\text { Я-творец } \\
\text { Мост к цели }\end{array}$ & $\begin{array}{l}\text { Вдохновение } \\
\text { Мое предназначение }\end{array}$ & Мой идеальный мир & $\begin{array}{l}4 \text { желания } \\
\text { Линия времени } \\
\text { Гнев-радость-страх- } \\
\text { печаль }\end{array}$ \\
\hline
\end{tabular}


пии, обучение эффективному управлению временными ресурсами, техникам тайм-менеджмента, работа с наращиванием ресурсов (психосинтез);

- интервенции в субъективное будущее реориентация жизненного стиля (А. Адлер), использование техник экзистенциального анализа, гештальттерапии для повышения осмысленности жизни, построение иерархии ценностей, поддержания веры, построения образов будущего.

Таким образом, проблема недостаточно высокого уровня субъективного благополучия матерей-одиночек может быть решена в процессе индивидуальной или групповой работы с использованием метафорических ассоциативных карт при воздействии на ось прошлого, настоящего, будущего в социальной, духовной, материальной, психологической сферах с опорой на различные психологические теории.

\section{СПИСОК ЛИТЕРАТУРЫ}

1. Аристотель. Никомахова этика / Аристотель // Аристотель. Сочинения : в 4 т. - М., 1984. - Т. 4. C. $65-68$

2. Братченко, С. Л. Личностный рост и его критерии / С. Л. Братченко, М. Р. Минюрова // Психологические проблемы самореализации личности. - СПб. : Речь, 2007. - С. 38-46.

3. Джидарьян, И. А. Психология счастья и оптимизма / И. А. Джидарьян. - М. : Ин-т психологии PAH, 2013. $-272 \mathrm{c}$.

4. Елисеева, О. А. Структура субъективного благополучия подростков в образовательной среде с низким уровнем психологической безопасности / О. А. Елисеева // Известия Российского государственного педагогического университета им. А.И. Герцена. - 2011. - № 132. - С. 368-375.

5. Киршке, В. Клубника за окном. Ассоциативные карты для коммуникации и творчества / В. Киршке. - Kirchzarten : Моритц Эгетмейер. ОН Verlag., 2010. -240 c.

6. Куликов, Л. В. Психогигиена личности. Вопросы психологической устойчивости и психопрофилактики / Л. В. Куликов. - СПб. : Питер, 2004. $464 \mathrm{c}$.

7. Люсова, О. В. Субъективное благополучие одиноких матерей: возможности арттерапии / О. В. Люсова // Одинокие матери в России. В чем проблема?: Теоретические подходы и прикладные исследования : материалы Всерос. науч.- практ. конф., г. Волгоград, 2-4 нояб. 2017 г. / редкол.: И. В. Черемисова (отв. ред.), И. В. Терелянская (зам. отв. ред.), И. А. Баракова (отв. секретарь) [и др.] ; Федер. гос. авт. образоват. учреждение высш. образования «Волгогр. гос. ун-т». Волгоград : Изд-во ВолГУ, 2017. - 164 с. - С. 54-61.

8. Маданес, К. Стратегическая семейная терапия / К. Маданес. - М. : Класс, 1999. - 272 с.

9. Попова, Г. В. Психологические механизмы применения метафорических ассоциативных карт в индивидуальном консультировании / Г. В. Попова, Н. Е. Милорадова // Проблеми сучасної педагогічної освіти : сб. ст. - Ялта : РВВ КГУ, 2014. Вып. 42. - Ч. 5. - С. 207-217.

10. Психотерапевтическая энциклопедия / под ред. Б. Д. Карвасарского. - 3-е изд., перераб. и доп. СПб. : Питер, 2006. - 944 с.

11. Пучкова, Г. Л. Субъективное благополучие как фактор самоактуализации личности : автореф. дис. ... канд. психол. наук / Пучкова Галина Леонидовна. - Хабаровск, 2003. - 17 с.

12. Рассказова, И. Н. Безбрачное одиночество женщин в период ранней взрослости / И. Н. Рассказова // Вестник Омского университета. Серия «Психология». - 2007. - № 1. - С. 20-29.

13. Селигман, М. Новая позитивная психология: научный взгляд на счастье и смысл жизни / М. Селигман. - М. : София, 2006. -368 c.

14. Суворова, О. В. Влияние эмоционального взаимодействия матери на самоотношение старшего дошкольника / О. В. Суворова, И. В. Черемисова, Е. Б. Мамонова // Вестник Мининского университета. - 2017. - № 1 (18). - Электрон. текстовые дан. Режим доступа: http://vestnik.mininuniver.ru/jour/ article/view/336 (дата обращения: 19.09.2017). - Загл. с экрана.

15. Трунов, Д. Использование метафор в психотерапевтической работе / Д. Трунов // Журнал практического психолога. - 1997. - № 1. - С. 14-20.

16. Шамионов, Р. М. Субъъективное благополучие личности: этнопсихологический аспект / Р. М. Шамионов // Проблемы социальной психологии личности. - Электрон. текстовые дан. - Режим доступа: http://psyjournals.ru/sgu_socialpsy/ issue/30315_full.shtml (дата обращения: 19.09.17). Загл. с экрана.

17. Argyle, M. The Psychology of Social Class / M. Argyle. - London : Routledge, 1994. - 313 p.

18. Assessing civic moral disengagement: dimensionality and construct validity/G. V. Caprara, R. Fida, M. Vecchione, C. Tramontano, C. Barbaranelli // Personality and Individual Differences. - 2009. Vol. 47, № 5. - P. 504-509.

19. Csikszentmihalyi, M. Flow: The Psychology of Optimal Experience / M. Csikszentmihalyi. - N. Y. : Harper and Row, 1990. - 303 p. 
20. Deci, E. L. The "What" and "Why" of Goal Pursuits: Human Needs and the Self-Determination of Behavior / E. L. Deci, R. M. Ryan // Psychological Inquiry. - 2000. - Vol. 11, № 4. - P. 227-268.

21. Diener, E. Factors predicting the subjective well-being of nations / E. Diener, M. Diener, C. Diener // Journal of Personality and Social Psychology. 1995. - Vol. 69. - P. 851-864.

22. Ryff, C. D. The structure of psychological wellbeing revisited / C. D. Ryff, C. L. M. Keyes // Journal of Personality and Social Psychology. - 1995. Vol. 69. - P. 719-727.

\section{REFERENCES}

1. Aristotle. Nikomakhova etika [The Nicomachean Ethics]. Sobr. soch.: v 4 t. [Collected Works: in 4 vols.]. Moscow, Mysl Publ., 1983, vol. 4, pp. 65-68.

2. Bratchenko S.L., Minyurova M.R. Lichnostnyy rost i ego kriterii [Personal Growth and Its Criteria]. Psikhologicheskie problemy samorealizatsii lichnosti [Psychological Problems of Self-Realization of Personality]. Saint Petersburg, Rech Publ., 1997, pp. 38-46.

3. Dzhidaryan I.A. Psikhologiya schastya $i$ optimizma [Psychology of Happiness and Optimism]. Moscow, Institut psikhologii RAN, 2013. 272 p.

4. Eliseeva O.A. Struktura subyektivnogo blagopoluchiya podrostkov $\mathrm{v}$ obrazovatelnoy srede $\mathrm{s}$ nizkim urovnem psikhologicheskoy bezopasnosti [The Structure of the Subjective Well-Being of Adolescents in an Educational Environment with a Low Level of Psychological Safety]. Izvestiya Rossiyskogo gosudarstvennogo pedagogicheskogo universiteta im. A.I. Gertsena, 2011, no. 132, pp. 368-375.

5. Kirshke V. Klubnika za oknom. Assotsiativnye karty dlya kommunikatsii i tvorchestva [Strawberry outside the Window. Associative Maps for Communication and Creativity]. Kirchzarten, Moritts Egetmeyer; OH Verlag, $2010.240 \mathrm{p}$.

6. Kulikov L.V. Psikhogigiena lichnosti. Voprosy psikhologicheskoy ustoychivosti i psikhoprofilaktiki [Psychohygiene of Personality. Questions of Psychological Stability and Psychoprophylaxis]. Saint Petersburg, Piter Publ., 2004. 464 p.

7. Lyusova O.V. Subyektivnoe blagopoluchie odinokikh materey: vozmozhnosti artterapii [Subjective Well-Being of Single Mothers: the Possibilities of Art Therapy]. Odinokie materi $v$ Rossii. $V$ chem problema?: Teoreticheskie podkhody i prikladnye issledovaniya: materialy Vseros. nauch.-prakt. konf., g. Volgograd, 2-4 noyab. 2017 g. [Single mothers in Russia. What is the Problem? Theoretical Approaches and Applied Research: Proceedings of the All-Russian
Research and Practice Conference, Volgograd, November 2-4, 2017]. Volgograd, Izd-vo VolGU, 2017, pp. 54-61.

8. Madanes K. Strategicheskaya semeynaya terapiya [Strategic Family Therapy]. Moscow, Klass Publ., 1999. $272 \mathrm{p}$.

9. Popova G.V., Miloradova N.E. Psikhologicheskie mekhanizmy primeneniya metaforicheskikh assotsiativnykh kart $\mathrm{v}$ individualnom konsultirovanii [Psychological Mechanisms of Application of Metaphorical Associative Maps in Individual Counseling]. Problemi suchasnoï pedagogichnoï osviti: sb. st. [Problems of Modern Pedagogical Education. Collected Articles]. Yalta, RVV KGU Publ., 2014, iss. 42, part 5, pp. 207-217.

10. Karvasarskiy B.D., ed. Psikhoterapevticheskaya entsiklopediya [Psychotherapeutic Encyclopedia]. Saint Petersburg, Piter Publ., 2006. 944 p.

11. Puchkova G.L. Subyektivnoe blagopoluchie kak faktor samoaktualizatsii lichnosti: avtoref. dis. ... kand. psikhol. nauk [Subjective Well-Being as a Factor of Self-Actualization of Personality. Cand. psychol. sci. abs. diss.]. Khabarovsk, 2003. 17 p.

12. Rasskazova I.N. Bezbrachnoe odinochestvo zhenshchin v period ranney vzroslosti [The Celibate Loneliness of Women During Early Adulthood]. Vestnik Omskogo universiteta. Seriya «Psikhologiya», 2007, no. 1, pp. 20-29.

13. Seligman M. Novaya pozitivnaya psikhologiya: nauchnyy vzglyad na schastye $i$ smysl zhizni [New Positive Psychology: A Scientific Look at Happiness and the Meaning of Life]. Moscow, Sofiya Publ., 2006. 368 p.

14. Suvorova O.V., Cheremisova I.V., Mamonova E.B. Vliyanie emotsionalnogo vzaimodeystviya materi na samootnoshenie starshego doshkolnika [Influence of the Mother's Emotional Interaction on the SelfAttitude of the Senior Preschooler]. Vestnik Mininskogo universiteta, 2017, no. 1 (18). URL: http:// vestnik.mininuniver.ru/jour/article/view/336. (accessed September 19, 2017).

15. Trunov D. Ispolzovanie metafor $\mathrm{v}$ psikhoterapevticheskoy rabote [The use of metaphors in psychotherapeutic work]. Zhurnal prakticheskogo psihologa [Journal of Practical Psychology], 1997, no. 1, pp. 14-20.

16. Shamionov R.M. Subyektivnoe blagopoluchie lichnosti: etnopsikhologicheskiy aspekt [Subjective Well-Being of the Person: Ethnopsychological Aspect]. Problemy sotsialnoy psikhologii lichnosti [Problems of Social Psychology of Personality]. URL: http://psyjournals.ru/ sgu_socialpsy/issue/30315_full.shtml. (accessed September 19, 2017).

17. Argyle M. The Psychology of Social Class. London, Routledge, 1994. 313 p. 


\section{РОССИЙСКАЯ СЕМЬЯ}

18. Caprara G.V., Fida R., Vecchione M., Tramontano C., Barbaranelli C. Assessing civic moral disengagement: dimensionality and construct validity. Personality and Individual Differences, 2009, vol. 47, no. 5, pp. 504-509.

19. Csikszentmihalyi M. Flow: The Psychology of Optimal Experience. New York, Harper and Row, $1990.303 \mathrm{p}$.

20. Deci E.L., Ryan R.M. The "What" and "Why" of Goal Pursuits: Human Needs and the Self-
Determination of Behavior. Psychological Inquiry, 2000, vol. 11, no. 4, pp. 227-268.

21. Diener E., Diener M., Diener C. Factors predicting the subjective well-being of nations. Journal of Personality and Social Psychology, 1995, vol. 69, pp. 851-864.

22. Ryff C.D., Keyes C.L.M. The structure of psychological well-being revisited. Journal of Personality and Social Psychology, 1995, vol. 69, pp. 719-727.

\section{Information about the Author}

Oksana V. Lyusova, Candidate of Psychological Sciences, Associate Professor, Department of Psychology, Volgograd Academy of Physical Culture, Lenina St., 78, 400005 Volgograd, Russian Federation, oxy180171@mail.ru.

\section{Информация об авторе}

Оксана Валерьевна Люсова, кандидат психологических наук, доцент кафедры психологии, Волгоградская академия физической культуры, ул. Ленина, 78, 400005 г. Волгоград, Российская Федерация, оху180171@mail.ru. 